Classification

Physics Abstracts

81.15Lm - 61.16-d

\title{
Analysis by scanning force microscopy of enzyme-containing Langmuir-Blodgett films elaborated by a horizontal lifting method
}

\author{
Stéphane Alexandre, Nicolas Dubreuil, Catherine Fiol and Jean-Marc Valleton
}

URA 500 CNRS, UFR des Sciences, Université de Rouen, 76821 Mont-Saint-Aignan, France

(Received 08 October, 1993; accepted 06 December, 1993)

\begin{abstract}
Résumé. - Un film de Langmuir-Blodgett mixte constitué d'acide béhénique et de glucose oxydase, transféré sur graphite pyrolytique a été étudié par microscopie à force atomique aux échelles microscopique et nanoscopique. Les résultats obtenus sont discutés par rapport à un modèle de la structure. Au niveau moléculaire, il est possible d'observer l'arrangement des molécules d'enzyme et leur structure individuelle mettant en jeu deux sous-unités.
\end{abstract}

\begin{abstract}
A mixed Langmuir-Blodgett film constituted of behenic acid and glucose oxidase transferred on HOPG has been studied by scanning force microscopy at microscopic and nanoscopic scales; the results concerning the structures observed at the atomic scale are discussed in reference with a model. At the molecular level, it was possible to observe the arrangement of enzyme molecules and their individual structure revealing their two subunits.
\end{abstract}

\section{Introduction.}

Langmuir-Blodgett films (LB films) have been studied for two decades for their remarkable properties and for their possibility of functionnalization by different types of molecules $[1,2]$. The main applications are in the domains of molecular electronics, non-linear optics, sensors. The latter domain concerns the gas media as well as liquid phases; in this case, biosensors play a particular role. The biosensors based on LB technique utilize an active layer constituted of one or several mixed layers of two types of molecules: an amphiphilic molecule mimicking the lipids of the biological membranes, and a biomolecule, the active component able to recognize specifically a chemical species. In most cases, the biomolecule involved in these systems is an enzyme [3-11]. A major problem encountered for designing these biosensors lies in the difficulty of organizing properly the structures at the molecular level.

The techniques of near field microscopies play a privileged role in the characterization of LB films [12-18]. Atomic Force or Scanning Force Microscopy (SFM) appears to be a powerfull tool for imaging these systems at a molecular level. However, only few papers deal with imaging of mixed layers of proteins and fatty acids [19-22]. 
In a previous paper [21], we published our first results concerning SFM images of a sample prepared by LB technique. This sample was constituted of two mixed layers of behenic acid and glucose oxidase (GOx). It was possible to observe the organization of the GOx molecules in ridges separated by approximately $6 \mathrm{~nm}$, and in some domains the presence of BA molecules on GOx structures. These measurements were performed in the air.

However, these first results did not allow the observation of individual molecules of enzyme. In addition, in this first work, no investigation was performed at the micron scale.

In this paper, we present new results concerning these mixed GOx-containing LB films transferred on HOPG. The particularity of this work is double:

- A horizontal lifting method was used for the transfer step [23]

- SFM measurements at the molecular scale were performed in a liquid phase.

The results presented here are discussed and compared with a model established after our results obtained with behenic acid monolayers formed on GOx solutions, and concerning pressuremolecular area isotherms, the adsorption of GOx at the interface, and a study of stability of behenic acid monolayers [24].

\section{Sample preparation.}

A Langmuir-Blodgett trough ATEMETA (Paris) was utilized for the preparation of the samples; the dimensions of the trough are $50 \mathrm{~cm} \times 7 \mathrm{~cm}$; the volume of the liquid phase is $250 \mathrm{~cm}^{3}$. This system uses a mobile barrier for compressing the amphiphilic molecules, and a Wilhelmy balance is used for measuring the interfacial pressure. The temperature of the subphase was $22{ }^{\circ} \mathrm{C}$ and the system operated in the air.

For the horizontal lifting procedure, the feedback loop (control of the mobile barrier by the signal produced by the Wilhelmy balance) was kept closed and a system with two articulations was used in order to keep the sample as horizontal as possible. However, in spite of this device, the transfer of the second layer constituting the bilayer formed by the horizontal transfer was quite asymmetrical.

For the elaboration of the mixed layer of behenic acid and glucose oxidase, an aqueous solution of glucose oxidase was used, and a behenic acid solution in chloroform was spread on its surface. Aqueous solutions were prepared with water obtained by a Millipore system involving deionization, reverse osmosis and filtration.

Glucose oxidase was obtained from SIGMA (type VII; Aspergillus niger) and used without further purification. Its concentration in the subphase was $3.2 \mathrm{mg} / \mathrm{l}$. Behenic acid (SIGMA, purity: 99\%) was prepared as a $10^{-3} \mathrm{M}$ solution in chloroform, and an amount of $0.1 \mathrm{ml}$ was spread with a micropipette. In order to obtain reproducible injections of behenic acid samples, a system was designed for positionning the pipette vertically, at a constant distance above the interface.

After spreading the behenic acid solution, the enzyme molecules were allowed to adsorb onto the polar heads of behenic acid molecules for $30 \mathrm{~min}$. Then the behenic acid molecules were compressed upto $30 \mathrm{mN} / \mathrm{m}$. After the compression, the film was transferred by the horizontal lifting method onto HOPG (highly oriented pyrolytic graphite) obtained from Le Carbonne Lorraine (Paris). The fact that a mixed bilayer system was formed by the transfer process was confirmed by transfer records. The horizontal lifting method has the particularity of producing samples which are completely covered by the Langmuir-Blodgett films, which facilitates the analysis by scanning force microscopy.

SFM experiments were performed with a Nanoscope II model from Digital Instruments (Santa Barbara, CA) with a $140 \mu \mathrm{m}$ scanner for large range analysis, and with a $1 \mu \mathrm{m}$ scanner for mole- 
cular resolution studies. Long range measurements were achieved in the air, whereas molecular resolution measurements were achieved in water by using the liquid cell.

All the measurements were performed with the feed-back loop on (constant force: $10^{-9}$ to $\left.10^{-8} \mathrm{~N}\right)$.

On long range images, no processing was used except a flatten operation used for obtaining the horizontality of graphite terraces. On high resolution images, in addition to the flatten operation, FFT filtering operations were made in some cases. All the images are presented in height mode (palette of colour for height: dark colours for low zones, light colours for high zones), and are 2D images.

\section{The model.}

Our studies on the structure and the stability of mixed monolayers formed by behenic acid on aqueous solutions of glucose oxidase [24] led to the establishment of a model showing the possibility for the enzyme i) to adsorb at the air/water interface between behenic acid molecules, ii) to adsorb below the polar heads of behenic acid molecules.

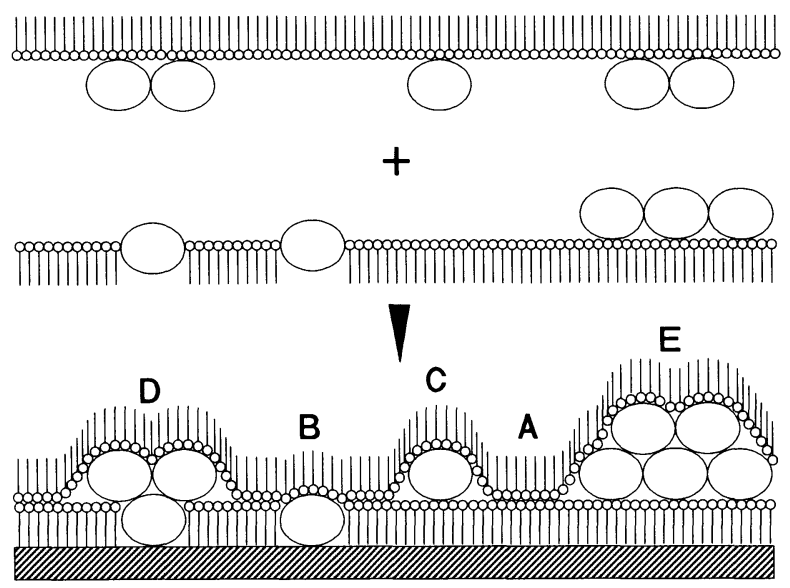

Fig. 1. - Tentative model of the structure of the mixed bilayer constituted of behenic acid and glucose oxidase obtained by the superposition of two mixed monolayer patches.

In this paper we utilize this first model to adapt it to the system resulting of a transfer, i.e. a mixed bilayer adsorbed on HOPG constituted of two patches of the mixed monolayer (Fig. 1). The model is based on some assumptions: i) the structure of the mixed monolayer is not perturbed by the transfer and the structure of the mixed bilayer results from the superposition of two patches of monolayer, ii) some configurations are rare [15]: for example, the simultaneous presence in the two monolayers of enzymes molecules alone (not covered by behenic acid) may be considered as very rare, iii) there is no hole in each monolayer.

The model takes into account typical situations which may be encountered; however, it cannot be considered as an exhaustive model taking into account all the possible configurations. Its purpose is to tentatively explain the SFM images. 

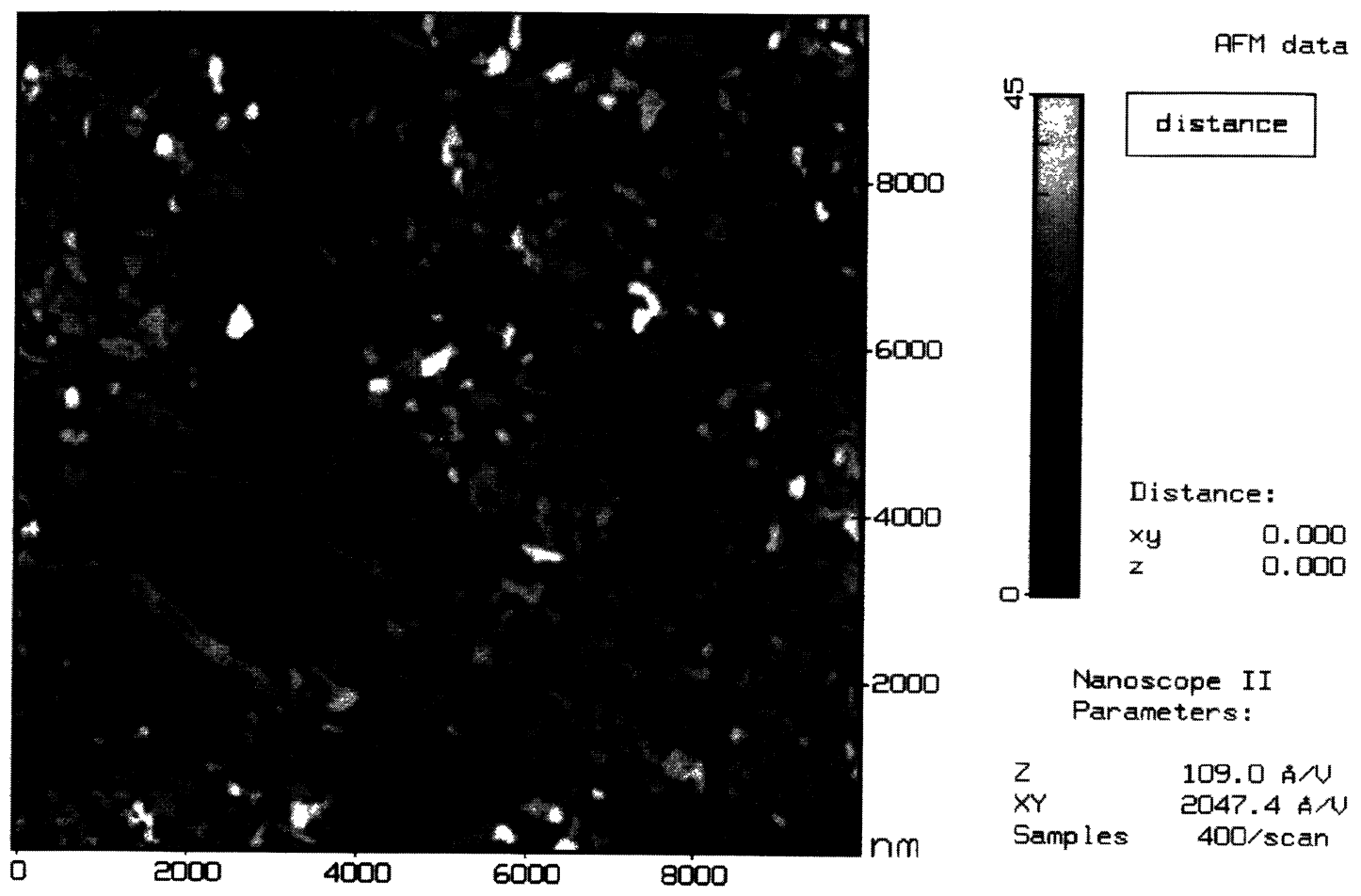

Fig. 2. - SFM image $10 \mu \mathrm{m} \times 10 \mu \mathrm{m}$ of the mixed bilayer constituted of behenic acid and glucose oxidase transferred on HOPG; glucose oxidase island structures are clearly visible.

Five typical situations are represented in the model (Fig. 1):

- A : no GOx in the two layers

- B : GOx at the interface of one layer

- C : 1 molecule (in the thickness) of GOx between the two layers

- D : GOx at the interface of one layer + GOx adsorbed on the other layer

- E : GOx adsorbed on one layer + GOx adsorbed on the other layer

Remark: The opposite situations of cases B and D may exist: no behenic acid would be present on the top of enzyme molecules.

In this model, only one layer of enzyme molecules adsorbed on behenic acid is considered; we shall see with the experimental results that this is a quite general situation.

It is difficult to estimate a priori the heights of the structures which will be observed in SFM measurements even if we assume that there is no hole in the behenic acid bilayer because: i) five cases have been considered in the model (A, B, C, D, E), ii) there are three possibilities of orientation of GOx molecules on a plane: the GOx molecule, constituted of two identical subunits, is schematically parallelepiped shaped [25]: $5.2 \times 6.0 \times 7.7 \mathrm{~nm}$. The combination of the different possibilities leads to a dozen of possibly observable heights; we shall see that some of them are more frequently observed than others. 

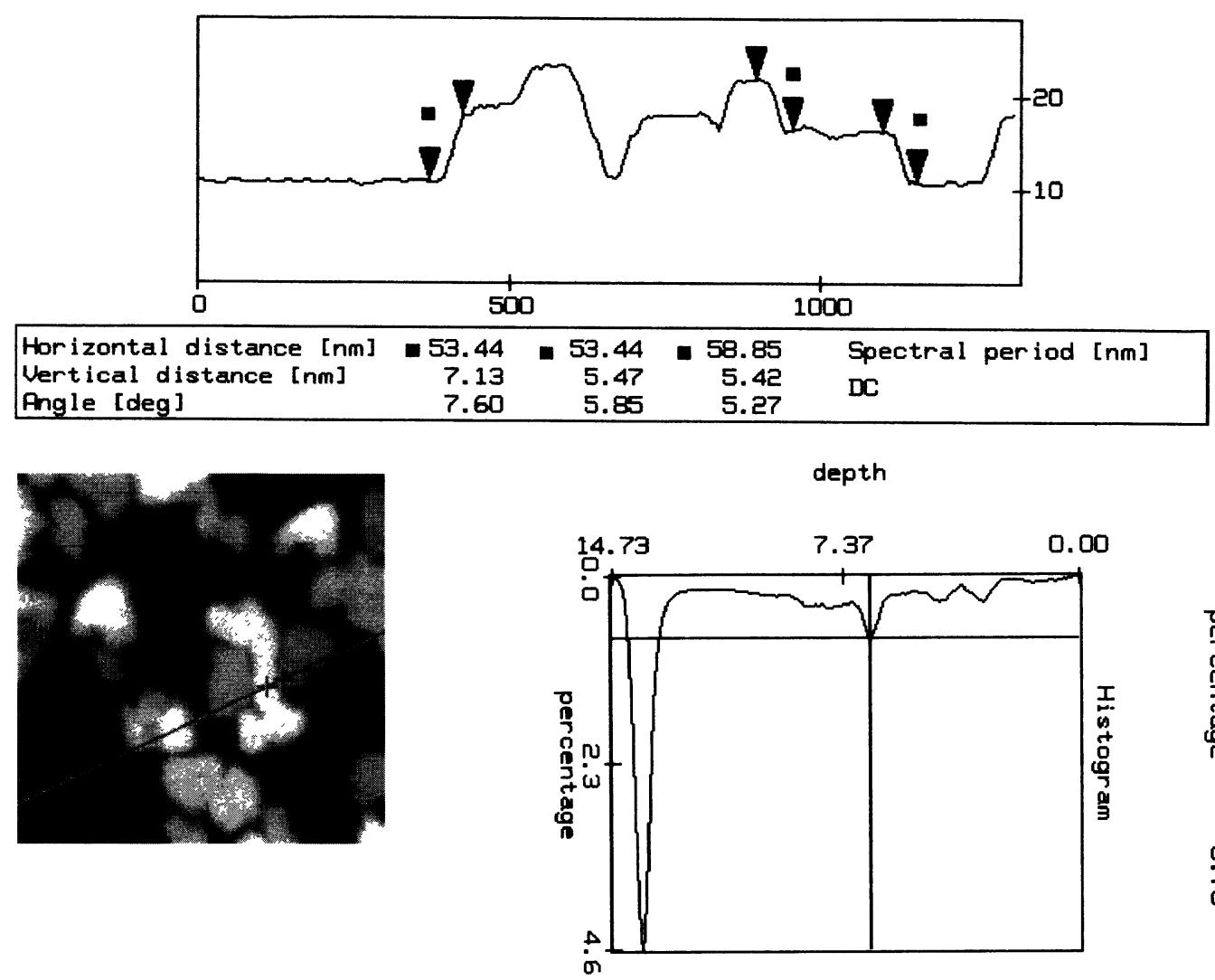

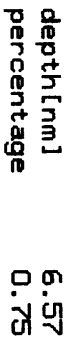

Fig. 3. - Section profile corresponding to a part of the image of figure 2; the heights of the structures observed are consistent with structural data concerning glucose oxidase.

\section{Results and discussion.}

At the microscopic scale, SFM measurements reveal a great heterogeneity (image $10 \mu \mathrm{m} \times 10 \mu \mathrm{m}$ of Fig. 2) characterized by randomly dispersed "islands" which may be attributed to enzymatic structures. This dispersion of enzyme islands is consistent with our model.

The coverage ratio of enzyme molecules is approximately $35 \%$; the layer of glucose oxidase is not continuous. The size polydispersity of enzymatic islands is important; the minimum characteristic length observed is about $50 \mathrm{~nm}$, which corresponds approximately to an island of 100 molecules; the largest islands occupy a surface of $0.1 \mu \mathrm{m}^{2}$.

It is possible to remark in figure 2 two types of defects on the graphite surface: the first defect is a step (approximately 10 planes of graphite) near a diagonal of the image (up-left to down-right); the second one, more visible, is a "strand" running from the left to the right limit of the image.

The image of figure 2 is informative in terms of in plane structures $(X Y)$; in order to appreciate the height of the enzymatic structures ( $Z$ information), we studied a section profile (Fig. 3 ) corresponding to a part of the image of figure 2 .

This profile is characterized by flat structures at different levels above the reference plane (assumed to be a behenic acid bilayer). The heights measured on this profile are 5.4, 6.5, 7.2, 10.8 and $12 \mathrm{~nm}$, which may be related respectively to the three characteristic dimensions of the glucose oxidase molecule [25], and to two combinations of these dimensions. In this part of the original 


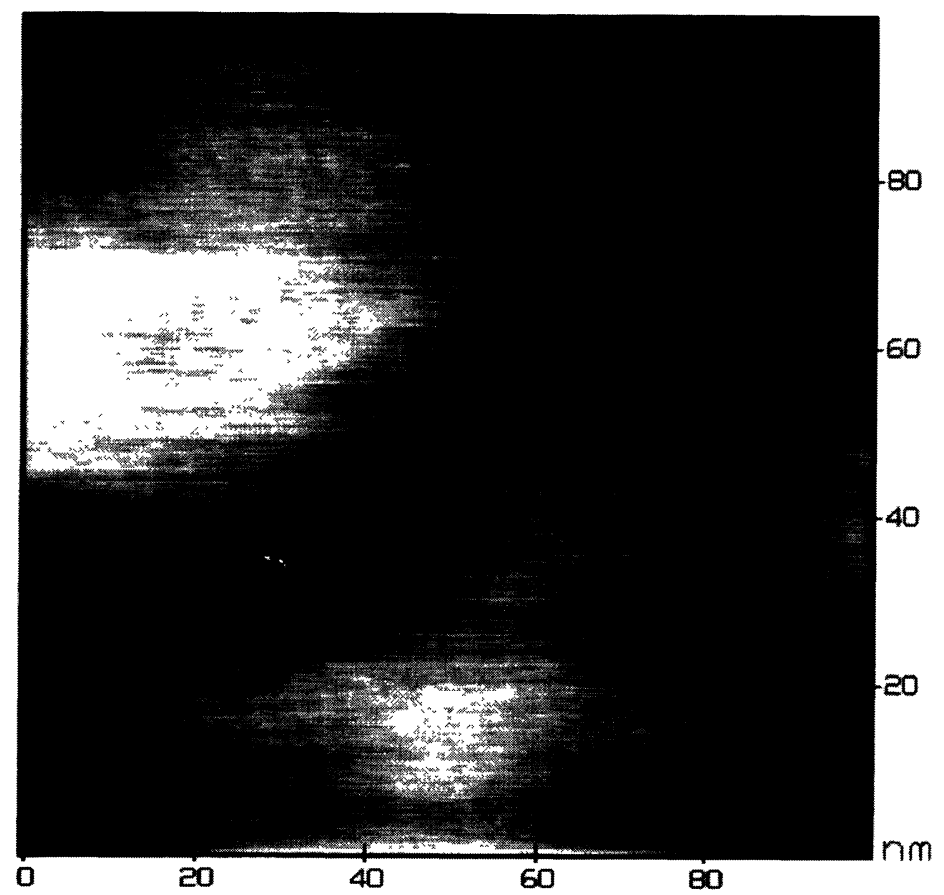

AFM data
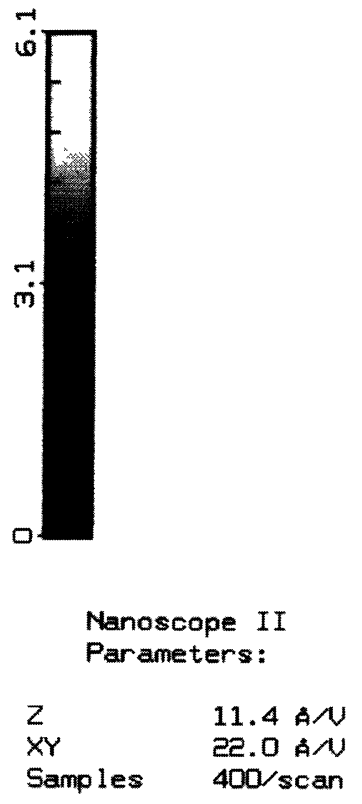

Fig. 4. - SFM image $100 \mathrm{~nm} \times 100 \mathrm{~nm}$ of the mixed bilayer constituted of behenic acid and glucose oxidase transferred on HOPG; the alignments separated by $6 \mathrm{~nm}$ may be attributed to enzymatic structures.

image there is no island whose height corresponds to more than two layers of enzyme. An histogram of the whole area of the image (Fig. 3) reveals a frequent height of $7.2 \mathrm{~nm}$.

The sample has then been studied at high resolution with the liquid cell. The first image, obtained without any processing, (Fig. 4) $(100 \mathrm{~nm} \times 100 \mathrm{~nm}$ ) corresponds to a part of an enzymatic island; alignments appear clearly, separated by approximately $6 \mathrm{~nm}$; they can be considered as enzymatic structures. These alignments themselves seem to be divided.

This result is consistent with our previous work concerning the observation of the same type of sample in the air [21], in which analogous structures were observed. Moreover, these periodicities have been obtained, independently of the angle of rotation, of the scan size and of the scan rate.

The image has then been processed by FFT, and the resulting image (Fig. 5) has been obtained by a filter used for removing very low frequencies and so flattening the surface of the sample in order to distinguish fine structures; the structure of the crystallization of GOx appears clearly. In several parts of the image, shifts between the alignments and slight changes of their orientation reveal defects in the crystalline order. The origin of these defects is not clear; they may be due to defects (steps) on the graphite plane; an other possible explaination might lie in the enzyme crystal growth process itself: the defects might be the frontiers between different crystals growing independently, until they meet, with slightly different orientations. 


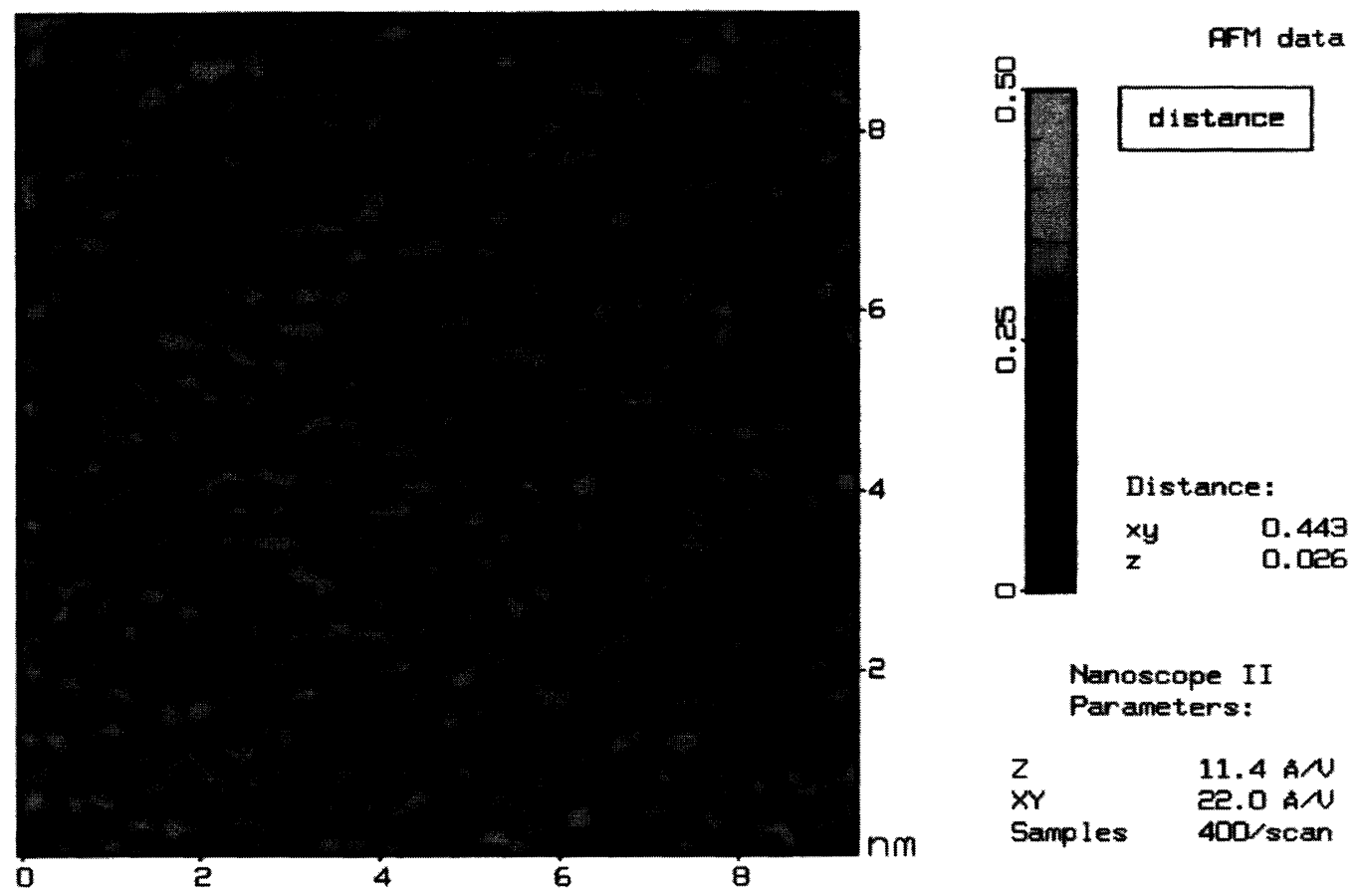

Fig. 5. - SFM image $100 \mathrm{~nm} \times 100 \mathrm{~nm}$ obtained by FFT processing of the image presented in figure 4; the structure of the crystallization of GOx is well defined; shifts between different parts of the image reveal several defects in the arrangement.

Image of figure 6 corresponds to an enlargment $(50 \mathrm{~nm} \times 50 \mathrm{~nm})$ of the right upper part of the image of figure 5 and a lowpass filter was applied; the two subunits of the glucose oxidase molecule are more visible (rectangle drawn around an enzyme molecule) and their dimensions are consistent with the data of the literature [25]. A small depression between the two subunits may be distinguished in several enzyme molecules, in agreement with these same data.

The image presented in figure 7 was obtained by FFT processing of a small part $(9.3 \mathrm{~nm} \times 9.3$ $\mathrm{nm}$ ) of an other image obtained with the same sample, by filtering and selecting the characteristic dimensions between $1 \mathrm{~nm}$ and $0.1 \mathrm{~nm}$; behenic acid molecules can be observed. The arrangement of these molecules presents some order, but this order is not perfect: this is probably due to the fact that the behenic acid layer lies on the enzyme matrix, and not on a "perfect" plane like a graphite surface. The distances observed between two molecules (about $4.5 \AA$ ) correspond well to structural data concerning this type of fatty acid [15-16].

\section{Discussion.}

A mixed Langmuir-Blodgett film constituted of behenic acid and glucose oxidase transferred on HOPG has been studied by scanning force microscopy; the images show, at the molecular level, the arrangement of enzyme molecules and their individual structure revealing the two subunits. On top of these molecules, it was possible to observe behenic acid molecules. These data are 

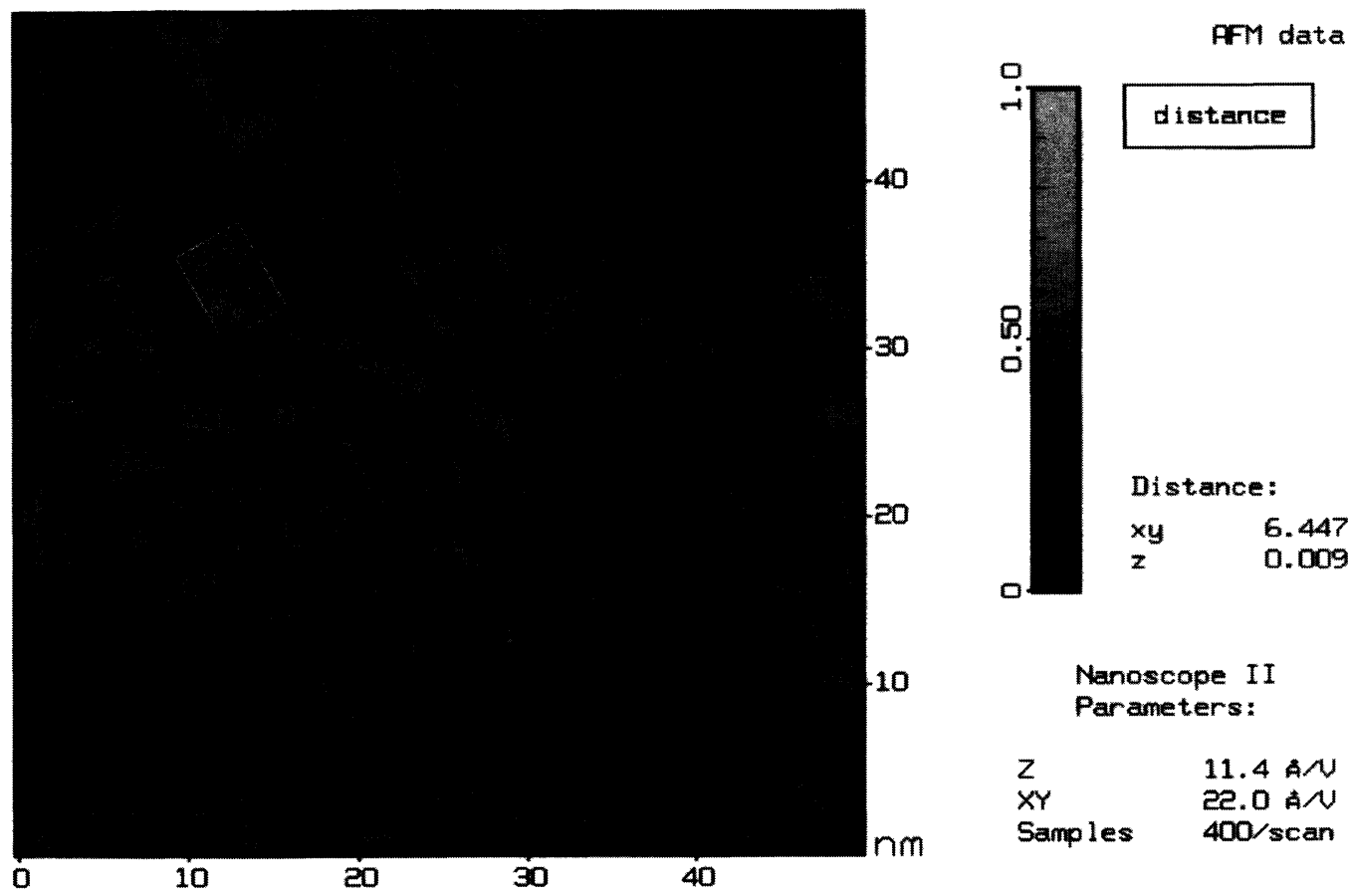

Fig. 6. - SFM image $50 \mathrm{~nm} \times 50 \mathrm{~nm}$ of the mixed bilayer constituted of behenic acid and glucose oxidase transferred on HOPG; this image corresponds to an enlargment of a part of the image of figure 5; the two subunits of the glucose oxidase molecule are clearly visible.

consistent with the model developed in this paper on the basis of our work concerning the structure of these mixed films at the air/water interface.

Enzyme molecules being covered by a behenic acid film, the obtention of a highly resolved structure of glucose oxidase is very difficult. In order to get better results, we shall try to elaborate a mixed structure in which GOx molecules are not covered by behenic acid.

The next step in our work will be to compare, by the same SFM technique, these mixed structures elaborated by this horizontal lifting method, and the classical vertical transfer method. The first scanning electron microscopy results seem to indicate a difference in the order, at least at a microscopic scale.

The natural evolution of this work devoted to mixed fatty acid/enzyme structures will be a better control of their arrangement, by varying different physical-chemical parameters. 

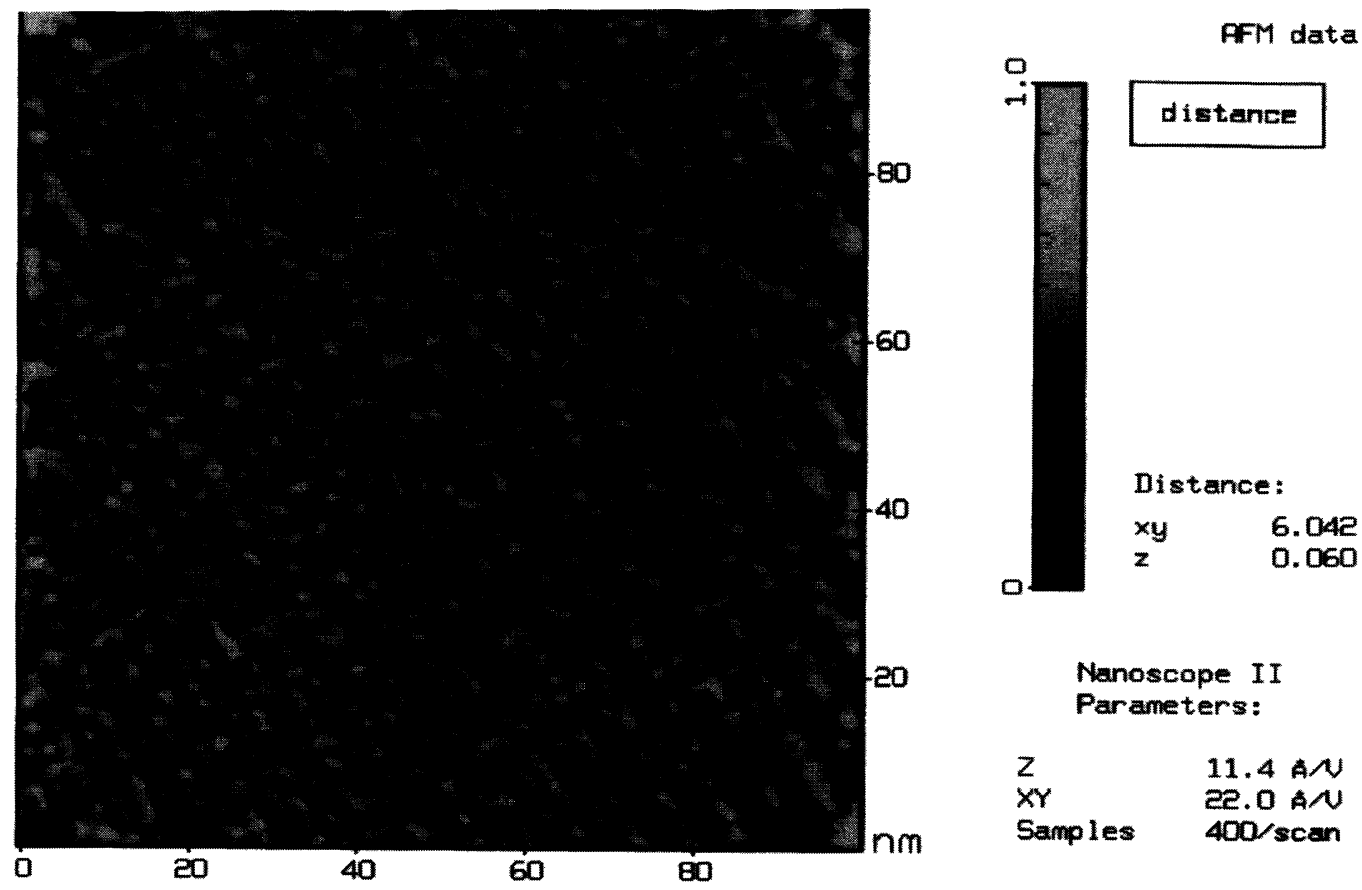

Fig. 7. - SFM image $9.3 \mathrm{~nm} \times 9.3 \mathrm{~nm}$ of the mixed bilayer constituted of behenic acid and glucose oxidase transferred on HOPG; this image was obtained by FFT processing of a part of an other image on the same sample; behenic acid molecules can be observed on top of enzyme molecules.

\section{References}

[1] Barraud A., Thin Solid Films 99 (1983) 317.

[2] Barraud A., J. Chim. Phys. 82 (1985) 683.

[3] Thompson M., Krull U.J., Trends Anal. Chem. 3 (1984) 173.

[4] Lowe C.R., Philos. Trans. R. Soc. London, Ser. B324 (1989) 487.

[5] Sriyudthsak M., Yamagishi H., Moriizumi T., Thin Solid Films 160 (1988) 463.

[6] Owaku K., Shinohara H., Ikariyama Y., Aizawa M., Thin Solid Films 180 (1989) 61.

[7] Anzai J., Lee S., Osa T., Chem. Pharm. Bull. 37 (1989) 3320.

[8] Schumann W., Heyn S.P., Gaub H.E., Adv. Mater. 3 (1991) 388.

[9] Arisawa S., Arise T., Yamamoto R., Thin Solid Films 209 (1992) 259.

[10] Turko I.V., Lepesheva G.I., Chashchin V.D., Anal. Chim. Acta 265 (1992) 21.

[11] Fiol C., Valleton J.M., Delpire N., Barbey G., Barraud A., Ruaudel-Teixier A., Thin Solid Films 210-211 (1992) 489.

[12] Weisenhorn A.L., Egger M., Ohnesorge F., Gould S.A.C., Heyn S.P., Hansma H.G., Sinsheimer R.L., Gaub H.E., Hansma P.K., Langmuir 7 (1991) 8.

[13] Alves C.A., Smith E.L., Porter M.D., J. Am. Chem. Soc. 114 (1991) 1222.

[14] Meyer E., Overney R., Brodbeck D., Howald L., Luthi R., Frommer J., Guntherodt H.J., Phys. Rev. Lett. 69 (1992) 1777.

[15] Schwartz D.K., Garanes J., Viswanathan R., Zasadzinski J.A.N., Science 257 (1993) 508.

[16] Bourdieu L., Ronsin O., Chatenay D., Science 259 (1993) 798.

[17] Peltonen J.P.K., He P., Rosenholm J.B., J. Amer. Chem. Soc. 114 (1992) 7637.

[18] Chi L.F., Eng L.M., Graf K., Fuchs H., Langmuir 8 (1992) 2255. 
[19] Egger M., Ohnesorge F., Weisenhorn A.L., Heyn S.P., Drake B., Prater C.B., Gould S.A.C., Hansma P.K., Gaub H.E., J. Struct. Biol. 1003 (1990) 89.

[20] Weisenhorn A.L., Drake B., Prater C.B., Gould S.A.C., Hansma P.K., Ohnesorge F., Egger M., Heyn S.P., Gaub H.E., Biophys. J. 58 (1990) 1251.

[21] Fiol C., Alexandre S., Delpire N., Valleton J.M., Thin Solid Films 215 (1992) 88.

[22] Fujiwara I., Ohnishi M., Seto J., Langmuir 8 (1992) 2219.

[23] Lee S., Virtanen J.A., Virtanen S.A., Penner R.M., Langmuir 8 (1992) 1243.

[24] Alexandre S., Dubreuil N., Fiol C., Valleton J.M., submitted.

[25] Hecht H.J., Kalisz H.M., Hendle J., Schmid R.D., Schomburg D., J. Biol. Mol. 229 (1993) 153. 